Nghiên cứu khuyến nghi cần tăng cường có các biện pháp cụ thể để nâng cao kiến thức về phòng ngừa ĐNN cho NLĐ, hướng dẫn sử dụng các thiết bị bảo hộ lao động cho công nhân chặt chẽ đảm bảo NLĐ luôn luôn sử dụng khi tiếp xúc với nguồn ồn và sử dụng đúng, hiệu quả. Cần thường xuyên đôn đốc, kiểm tra giám sát việc sử dụng thiết bị bảo hộ của NLĐ tự ý không sử dụng do chủ quan hoặc thiếu kiến thức hoặc sử dụng không đúng như yêu cầu.

\section{TÀI LIÊU THAM KHẢO}

1. World Health Organization (2016), WHO global estimates on prevalence of hearing loss, http://www. who. int/pbd/deafness/WHO GE HL. pdf.

2. World Health Organization (2017), WHO methods and data sources for global burden of disease estimates 2000-2015, Department of Information, Evidence and Research WHO, Geneva.

3. Theo Vos \& et al (2015), "Global, regional, and national incidence, prevalence, and years lived with disability for 301 acute and chronic diseases and injuries in 188 countries, 1990-2013: a systematic analysis for the Global Burden of
Disease Study 2013", The Lancet. 386(9995), page. 743-800.

4. Elizabeth A Masterson (2016), "Hearing impairment among noise-exposed WorkersUnited States, 2003-2012", MMWR. Morbidity and mortality weekly report. 65 .

5. GV Prasanna Kumar \& et al (2008) "Occupational noise in rice mills", Noise and Health. 10(39), page. 55.

6. Đố Văn Hàm (2007), "Tiếng ồn trong sản xuất và điếc nghề nghiệp", trong Đố Văn Hàm, chủ biên, Sức khỏe nghề nghiệp, Nhà xuất bản $Y$ học Hà Nội, Hà̀ Nội

7. Nguyển Đăng Quốc Chấn và Bùi Đại Lịch (2008), "Kiến thức, thái độ, hành vi phòng chống ô nhiễm tiếng ôn và điếc nghề nghiệp của công nhân môt số nhà máy, xí nghiêp có tiếng ồn cao (> 85dBA) tại thành phố Hồ Chí Minh", Y học thành phố Hồ Chí Minh. 12(4), tr. 226-228

8. Emmanuel D Kitcher \& et alc (2014), "Occupational hearing loss of market mill workers in the city of Accra, Ghana", Noise and Health. $16(70)$, page. 183

9. Tim Robinson \& et al (2015), "Prevalence of noise-induced hearing loss among woodworkers in Nepal: a pilot study", International journal of occupational and environmental health. 21(1), page. $14-22$

\title{
KHẢO SÁT NHU CẦU SỬ DỤNG DICH VỤ CHĂM SÓC SỨC KHỎE NộI TRÚ BAN NGÀYY (DAYCARE) CỦA NGƯỜI CAO TUỔI TẠI QUÂ̂N SƠN TRÀ, TP.ĐÀ NÃ̃NG
}

\section{TÓM TẮT}

Mục tiêu nghiên cứu: Xác định nhu cầu về dịch vu chắm sóc sức khỏe nôi trú ban ngày của người cao tuổi tại quận Sơn Trà thành phố Đà Nẵng và mô tả một số yếu tố liên quan đến nhu cầu sử dung dịch vu nêu trên. Đối tượng nghiên cứu: Người cao tuổi đang sinh sống tại quận Sơn Trà, thành phố Đà Nẵng. Tiêu chuẩn chọn: Người cao tuổi ( $\geq 60$ tuội) đang sinh sống tại Quận Sơn Trà, thành phố Đà Nẵng. Với người cao tuổi không đủ minh mẫn để hoàn thiện bộ câu hỏi thì người nhà/người thân là người tham gia nghiên cứu. Không có các dấu hiệu của tổn thương về tinh thần và nhận thức ảnh hưởng đến việc trá lời hoàn thiện bộ cẩu hỏi. Đồng ý tham gia nghiên cứu này. Tiêu chuẩn loai trừ: Những người không đồng ý tham gia vào nghiển cứu sau khi được giải thích rõ mục đích và mục tiêu của nghiên cứu. Các đối tượng không đáp ứng được các tiêu chuẩn nói trên. Phươnng

*Bệnh viện 199 thành phỗ Đà Nẵng

Chịu trách nhiệm chính: Võ Thị Hồng Hướng

Email: drhonghuong@gmail.com

Ngày nhận bài: 15.3.2021

Ngày phản biên khoa học: 10.5.2021

Ngày duyệt bài: 18.5.2021

\section{Quách Hũu Trung*, Võ Thị Hồng Hướng*}

pháp nghiên cứu: Nghiên cứu mô tả cắt ngang có phân tích được thực hiện từ tháng 15/4/2021 đến tháng 25/04/2021 trên 188 người cao tuối đang cư trú tại quận Sơn Trà, thành phố Đà Nẵng bằng hình thức phỏng vấn trực tiếp. Bộ câu hỏi đước thiết kế sẵn sử dụng các câu hỏi đóng để thuận tiện cho đối tượng nghiên cứu trả lời. Kêt quả: Với 188 người cao tuổi tại quận Sơn Trà, thành phố Đà Nẵng tham gia khảo sát nghiên cứu, cho thây rằng người cao tuối có nhu cầu sử dụng dịch vụ chăm sóc ban ngày tuy nhiên mức độ nhu cầu không cao; có 03 yếu tố có mối liên quan có ý nghĩa thống kê (với $p<0,05)$, bao gồm: mức kinh tế gia đình; nghề nghiệp và từng nghe về dịch vụ chăm sóc ban ngày. Kết luận: Nghiên cứu chỉ ra nhu câu sử dụng dịch vụ chăm sóc nội trú ban ngày sẽ được chú ý và quan tâm hơn khi người dân hiểu rõ hơn về dịch vụ này, đồng thời dịch vụ này cũng sẽ có nhiều khả năng được quan tâm hơn ở những đối tượng có điều kiện về kinh tế. Do vậy, để phát triển các dịch vụ y tế mới trong đó có dịch vụ chăm sóc nội trú ban ngày cho người cao tuổi, cần tăng cường công tác tuyên truyền, quảng bá về loại hình dịch vụ này đến đông đảo người dân và cộng đồng, tập trung ưu tiên nhóm đối tượng có mức kinh tế cao. tuổi.

Tư khóa: Chăm sóc nội trú ban ngày, người cao 


\section{SUMMARY \\ SURVEY OF THE NEED TO USE DAYCARE HEALTH SERVICES OF ELDERLY IN SON TRA DISTRICT, DA NANG}

Objective: (1) Identify the elderly's needs for using daycare health services in Son Tra district, Da Nang city; (2) Describe some factors related to the need to use the above services. Subjects: The elderly are living in Son Tra district, Da Nang city. Criteria to choose: Elderly people ( $\geq 60$ years old) are living in Son Tra District, Da Nang City. For the elderly who could not be complete the questionnaire, family members / relatives are the participants in the study. There are no signs of mental or cognitive injury affecting a complete questionnaire response. Agree to participate in this study. Exclusion criteria: People who do not agree to participate in the study after being clearly explained to the purpose and objectives of the study. Subjects that do not meet the above standards. Methods: A descriptive cross-sectional study was conducted in April 15-25, 2021, on 188 elderly people are residing in Son Tra district, Da Nang city by directly interviews. The pre-designed questionnaire uses closed-ended questions for the study subjects that can answer easily. Results: In total 188 respondents completed the questionaire who living in Son Tra district, Da Nang city participating in a research survey, it shows that elderly people also have a need to use daycare services, however, the level of demand is not high with mean values; there are 03 factors that have a statistically significant relationship (with $\mathrm{p}<0.05$ ), including: economic level; occupation and have heard about daycare before. Conclusions: The study showed that the need for using day care services will be more attentive and concerned when people better understand this service, and this service will also be more interested in those with hight economic conditions. Therefore, in order to develop new medical services, including daycare service for the elderly, it is necessary to strengthen the propaganda and promotion of this type of service to community, focus on priority groups with high economic level.

Keywords: Daycare, elderly.

\section{I. ĐẶT VẤN ĐỀ}

Hiên nay, tuổi tho trung bình của người dân tại thành phố Đà Nănng đạt 76 tuổi [1], cao hơn tuổi thọ trung bình chung của cả nước. Quá trình già hóa dân số diễn ra với tốc độ nhanh chóng đã tạo nên thách thức lớn về sự cần thiết phải có những giải pháp thích ứng, phù hợp về các dịch vụ an sinh xã hội, lao động việc làm, giao thông, khu vui chơi giải trí... đặc biệt là hệ thống chăm sóc sức khỏe người cao tuổi. Người cao tuổi Việt Nam nói chung và thành phố Đà Nẵng nói riêng đang phải đối diện với gánh nặng bệnh tật và thường mắc nhiều bệnh mãn tính, đối diện với nguy cơ tàn phế do quá trình lão hóa và ngày càng gia tăng chi phí, chăm sóc, điều trị, nuôi dưỡng... Trong khi đó, hệ thống chăm sóc sức khỏe người cao tuổi chưa đáp ứng.

Ngoài ra, cuộc cách mang công nghệ 4.0 đã và đang thay đổi cuộc sống của con người về nhiều mặt, có nhiều dịch vụ y tế mới ra đời, song song với dịch vụ chăm sóc ban ngày trong đó dịch vụ khám chữa bệnh từ xa (Telemedicine) được coi là một cuộc đại cách mạng trong cách thức cung cấp dịch vụ y tế [2]. Dịch vụ chăm sóc ban ngày hay y tế từ xa giúp người dân chủ động sắp xếp thời gian chăm sóc sức khỏe, kiểm soát tốt hơn tình trạng bệnh, được chăm sóc sinh hoạt hằng ngày tốt hơn, đặc biệt thay những người con, người cháu chăm sóc tốt cho người cha, người me của họ...

Tại Đà Nẵng, Bệnh viện 199 là một trong những cơ sở y tế đầu tiên trên địa bàn quận Sơn Trà, thành phố Đà Nẵng có cung ứng dịch vụ chăm sóc sức khỏe ban ngày cho người cao tuổi, chăm sóc người cao tuổi tại nhà ...Vì vậy, để góp phần có kế hoạch phát triển mô hình dịch vụ chăm sóc ban ngày được phát huy hết lợi thế và tăng khả năng tiếp cận của người cao tuổi đối với dịch vụ này, nhóm nghiên cứu Bệnh viện 199 Đà Nẵng tiến hành khảo sát "Nhu cầu sử dụng dịch vụ chăm sóc sức khỏe nội trú ban ngày của Người cao tuổi tại Quận Sơn Trà, thành phố Đà Nắng" với 02 mục tiêu cụ thể:

1. Xác định nhu cầu về dịch vụ chăm sóc sức khỏe nội trú ban ngày của người cao tuổi tại quận Sơn Trà, thành phố Đà Nẵng.

2. Mô tá một số yếu tố liên quan đến nhu cầu sử dụng dịch vụ chăm sóc ban ngày của người cao tuổi tại quận Sơn Trà, thành phố Đà Nẵng.

\section{II. ĐỐI TƯợNG VÀ PHƯƠ'NG PHÁP NGHIÊN CỨU}

+ Đối tượng nghiên cứu: Người cao tuổi đanng sinh sống tại quận Sơn Trà, thành phố Đà Nẵng.

+ Phương pháp nghiên cứu: Nghiên cứu mô tả cắt ngang có phân tích được thực hiện trên 188 người cao tuổi đang cư trú tại quận Sớn Trà, thành phố Đà Nẵng bằng hình thức phỏng vấn trực tiếp. Hệ số tin cậy của thang đo đánh giá nhu cầu và các biến nhân tố liên quan Cronbach Anpha = 0,80 (có độ tin cậy cao).

\section{- Biến số nghiên cứu:}

\begin{tabular}{|c|c|c|}
\hline Biến số & $\begin{array}{c}\text { Công } \\
\text { cụ } \\
\text { thù } \\
\text { thập }\end{array}$ & $\begin{array}{c}\text { Kỹ } \\
\text { thuật } \\
\text { thự } \\
\text { thập }\end{array}$ \\
\hline \multicolumn{2}{|c|}{ Thông tin chung về đối tượng nghiên cứu } \\
\hline \multicolumn{2}{|c|}{ Tuối } & Phỏng \\
\hline
\end{tabular}


VIETNAM MEDICAL JOURNAL N¹ - JUNE - 2021

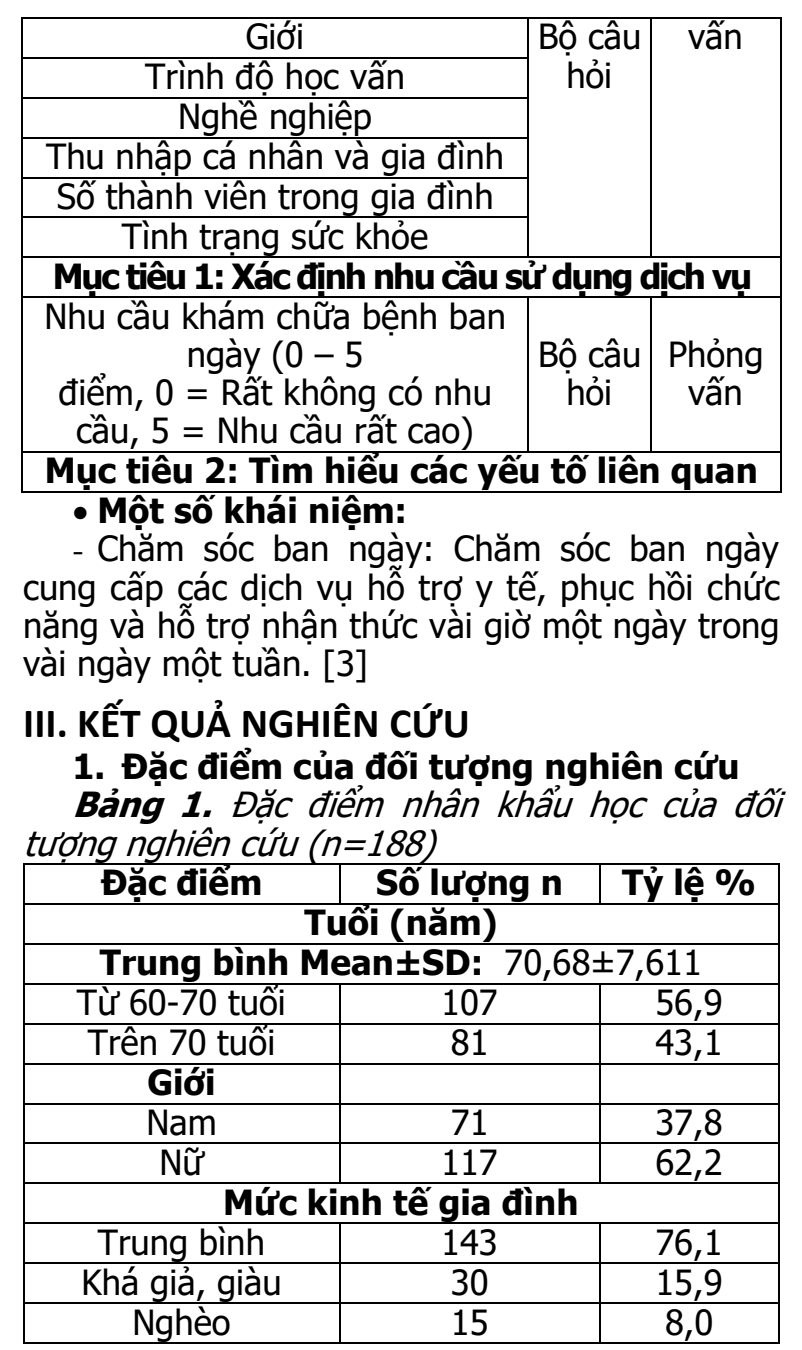

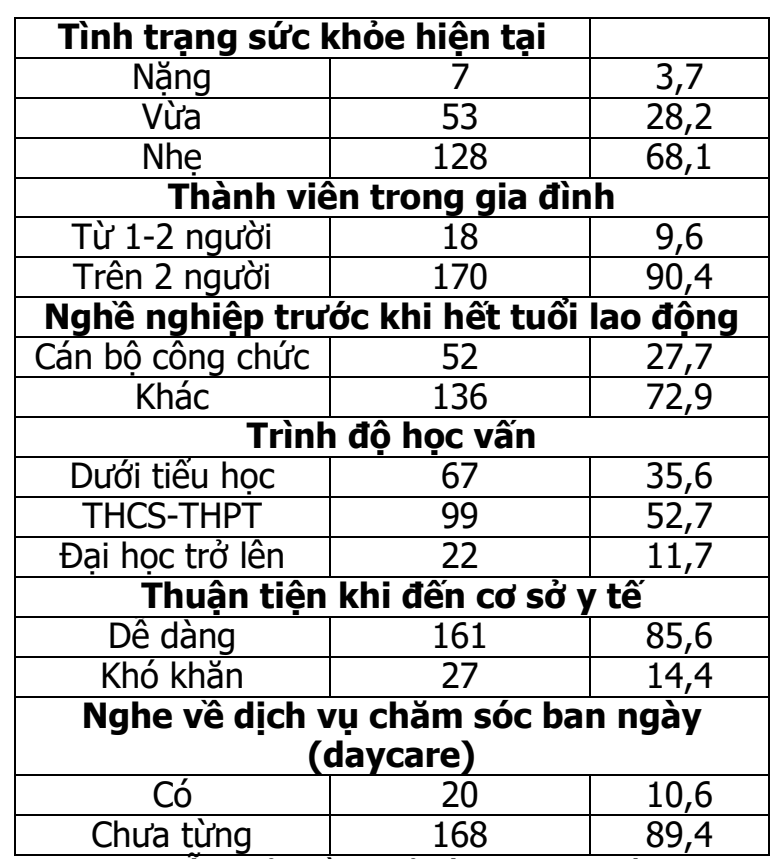

Được diến giải bằng tỷ lệ \%hoặc giá trịtrung bình \pm độ lệch chuẩn.

Nhận xét: Độ tuổi trung bình là 70,68 \pm 7,611 ; tỷ lệ người cao tuổi là nữ chiếm gấp đôi so với người cao tuổi nam lần lượt tỷ lệ là $62,2 \%, 37,8 \%$; có $27,2 \%$ là cán bộ công chức về hưu còn lại là các ngành nghề khác như lao động tự do, buôn bán... Đặc biệt trong số các thông tin ghi nhận chỉ có $10,6 \%$ đối tượng nghiên cứu đã từng nghe về dịch vụ chăm sóc sức khỏe nội trú ban ngày.

2. Nhu câu của người cao tuổi trong các dịch vụ chăm sóc ban ngày

Bảng 2. Nhu cầu của từng loại hình dịch vụ

\begin{tabular}{|c|c|c|c|}
\hline Loại dịch vụ & Có nhu câu & Không có nhu câu & Điếm TB \pm SD \\
\hline $\begin{array}{c}\text { Chăm sóc nội trú ban ngày vào } \\
\text { các ngày thường }\end{array}$ & $110(58,5 \%)$ & $78(41,5 \%)$ & $1,4 \pm 1,557 / 4$ \\
\hline
\end{tabular}

Nhận xét: người cao tuối cũng cho rằng cũng có nhu cầu sử dụng dịch vụ chăm sóc ban ngày vào các ngày thường tuy nhiên mức độ nhu cầu không cao với các giá trị trung bình là 1,4 1,557/4.

3. Mối liên quan giữa một số yếu tố đến nhu câu chăm sóc ban ngày

Bảng 3. Các yếu tố liên quan

\begin{tabular}{|c|c|c|c|}
\hline Đặc điểm & $\begin{array}{l}\text { Không có } \\
\text { nhu câu }\end{array}$ & Có & Giá trị p \\
\hline Tuối (năm) : Từ 60-70 tuối & $45(42,1 \%)$ & $62(57,9 \%)$ & \multirow{2}{*}{$p=0,488>0,05$} \\
\hline Trên 70 tuối & $33(40,7 \%)$ & $48(59,3 \%)$ & \\
\hline : Nam & $27(38,0 \%)$ & $44(62,0 \%)$ & \multirow{2}{*}{$p=0,276>0,05$} \\
\hline Nũ̃ & $51(43,6 \%)$ & $66(56,4 \%)$ & \\
\hline Mức kinh tế gia đình: Trung bình, nghèo & $72(45,6 \%)$ & $86(54,4 \%)$ & \multirow{2}{*}{$p=0,007<0,05$} \\
\hline Khá giả, giàu & $06(20,0 \%)$ & $24(80,0 \%)$ & \\
\hline Tình trạng sức khỏe hiện tại: Nặng & $02(28,6 \%)$ & $05(71,4 \%)$ & \multirow{3}{*}{$p=0,714>0,05$} \\
\hline Vừa & $21(39,6 \%)$ & $32(60,4 \%)$ & \\
\hline Nhẹ & $55(43,0 \%)$ & $73(57,0 \%)$ & \\
\hline
\end{tabular}




\begin{tabular}{|c|c|c|c|}
\hline Thành viên trong gia đình & & & \\
\hline Từ 1-2 người & $7(38,9 \%)$ & $11(61,1 \%)$ & \multirow{2}{*}{$p=0,511>0,05$} \\
\hline Trên 2 người & $71(41,8 \%)$ & $99(58,2 \%)$ & \\
\hline \multicolumn{4}{|l|}{ Nghề nghiệp trước khi hết tuối lao động } \\
\hline Cán bộ công chức & $16(30,8 \%)$ & $36(69,2 \%)$ & \multirow{2}{*}{$p=0,046<0,05$} \\
\hline Khác & $62(45,6 \%)$ & $74(54,4 \%)$ & \\
\hline Trình độ học vấn: Dưới tiếu học & $29(43,3 \%)$ & $38(56,7 \%)$ & \multirow{3}{*}{$\mathrm{p}=0,761>0,05$} \\
\hline THCS-THPT & $40(40,4 \%)$ & $59(59,6 \%)$ & \\
\hline Đại học trở lên & $09(40,9 \%)$ & $13(59,1 \%)$ & \\
\hline Thuận tiện khi đến cơ sở y tế: Dê dàng & $67(41,6 \%)$ & $94(58,4 \%)$ & \multirow{2}{*}{$p=0,553>0,05$} \\
\hline Khó khăn & $11(40,7 \%)$ & $16(59,3 \%)$ & \\
\hline \multicolumn{3}{|c|}{ Nghe về dịch vụ chăm sóc ban ngày (daycare) } & \multirow{3}{*}{$p=0,031<0,05$} \\
\hline Có & $04(20,0 \%)$ & $16(80,0 \%)$ & \\
\hline Chưa từng & $74(44,0 \%)$ & $94(56,0 \%)$ & \\
\hline
\end{tabular}

Nhận xét: có 03 yếu tố có mối liên quan có ý nghĩa thống kê (với $p<0,05)$, bao gồm: mức kinh tế gia đình; nghề nghiệp và từng nghe về dịch vụ chăm sóc ban ngày.

\section{BÀN LUÂN}

Quận Sơn Trà là một quận ở khu vực nội thành nên thu nhập kinh tế của người dân nhìn chung cũng khá cao và ổn định. Đây sẽ là những đối tượng có khả năng sử dụng các dịch vụ chăm sóc ban ngày cao chưa kể đến có nhu cầu hay không nhưng họ có khả năng chi trả cho các phí có dịch vụ gia tăng hoặc phí dịch vụ tự chi trả.

Hơn $1 / 2$ đối tượng nghiên cứu đều cho rằng nên triển khai các dịch vụ y tế CSSK ban ngày, gồm các ngày thường trong tuần là $58,2 \%$ khách hàng ủng hộ. Mặc dù, mức độ nhu cầu được đánh giá không cao tuy nhiên có thể thấy nhóm đối tượng nghiên cứu tuy chưa từng được nghe và biểt về dịch vụ chăm sóc ban ngày là như thế nào nhưng người dân cũng đã có những nhìn nhận quan tâm ban đầu đến loại hình dịch vụ này (chỉ có $10,6 \%$ đối tượng nghiên cứu đã từng nghe về dịch vụ chăm sóc sức khỏe nội trú ban ngày).

Với tâm lý chung, người cao tuổi vần mong muốn được ở nhà bên cạnh con cháu, tuy nhiên với nhịp sống ngày càng sôi động, hằng ngày người cao tuổi thường chỉ ở nhà một mình do con cháu đều đi làm hoăc đi hoc, do vậy nhu cầu có bạn bè giao lưu, môi trường giải trí nhưng đảm bảo không gian ấm cúng như một gia đình là điều mà nhiêu người cao tuổi luôn mong đợi. Ngoài ra, việc có người chăm sóc, trò chuyện sẽ giúp cho người già không còn cảm thấy tủi thân và họ sẽ vui vẻ, yêu đời cũng như khi được chăm sóc đầy đủ thì tình trạng sức khỏe cũng sẽ tốt hơn rất nhiều lần. [4]

Tương tự nghiên cứu tại Hải Dương cho rằng người cao tuổi có tỷ lệ mắc bệnh cao và dễ bị tổn thương về sức khỏe thể chất, tinh thần và xã hội hơn các nhóm tuổi khác. Nhu cầu CSSK cho người cao tuổi rất lớn, không đơn thuần dựa vào thuốc và một số trị liệu, về lâu dài cần có các giải pháp hợp lý để họ tự giữ gìn và nâng cao sức khỏe của mình cũng như nhận được sự hỗ trợ thiết thực từ gia đình, cộng đồng và xã hội. [5].

Có thể nói, người cao tuổi là đối tượng cần được quan tâm đến vấn đề sức khỏe nhiều hơn các đối tượng khác do họ thường có nhiều bệnh lý nền, tuy nhiên sự hỗ trợ này hiện nay chưa được quan tâm đúng mực. Theo Trần Thị Hạnh (2008) nghiên cứu về thực trạng CSSK cho người cao tuổi cho biết có $16 \%$ chưa nhận được sự bổ trợ hợp lí của gia đình và cộng đồng, một nửa người cao tuổi cảm thây rằng họ không khỏe. Điều nay cho thấy nhu cầu kiểm tra sức khỏe cho NCT là hết sức bức thiết [6].

Qua phân tích các yếu tố liên quan cho thây với dịch vụ chăm sóc ban ngày vào các ngày thường trong tuần thì có 03 yếu tố chính ảnh hưởng lên nhu cầu sử dụng dịch vụ là mức kinh tế gia đình; nghề nghiệp và từng nghe về dịch vụ chăm sóc ban ngày. Trong đó, tỷ lệ người cao tuổi có nhu cầu sử dụng dịch vụ chăm sóc ban ngày vào các ngày thường có mức kinh tế gia đình khá giả và giàu cao hơn gấp 4 lần so với nhóm người cao tuổi còn lại với mức kinh tế nghèo, trung bình (lần lượt là $80,0 \%$ và $20,0 \%$ ), sự khác biệt này có ý nghî̉a thống kê với $p<0,05$. Kết quả nghiên cứu này cũng tương tự như nghiên cứu của tác giả Bùi Thùy Dương (2010) [7], cùng xác định yếu tố về mức kinh tế có liên quan đến nhu cầu sử dụng dịch vụ ngoài giờ, tại nhà tương tự như dịch vụ chăm sóc nội trú ban ngày.

Tại nghiên cứu này cũng ghi nhận rằng tỷ lệ người cao tuổi có nhu câu sử dụng dịch vụ chăm sóc ban ngày vào các ngày thường thuộc nhóm cán bộ công chức cao hơn gấp 2 lần so với nhóm người cao tuổi còn lại với các ngành nghề khác (lân lượt là $69,2 \%$ và $30,8 \%$ ), sự khác biệt này 
có ý nghĩa thống kê với $p<0,05$. Điều này có thể hiểu rằng, những người cao tuổi trước đây là cán bộ công chức thì họ có mối quan hệ xã hội cũng như kiến thức nhất định liên quan đến việc cần chăm lo sức khỏe cũng như độc lập, tự chủ về tài chính do đó họ thường biết tự quyết định các giải pháp chăm lo cá nhân của bản thân được tốt hơn so với nhóm đối tượng còn lại ở các ngành nghề khác.

Một nội dung được ghi nhận thông qua nghiên cứu này nên đáng được quan tâm hơn để góp phần có giải pháp phát triển bất kỳ loại hình dịch vụ mới nào, không riêng dịch vụ vè y tế, đó là khách hàng cần được nắm các thông tin liên quan đến dịch vụ mình sẽ sử dụng, từ đó nhu câu sử dung sẽ được tăng cao hơn. Do vây, với nghiên cứu này cũng ghi nhận được rằng nhóm người cao tuổi đã từng nghe về dịch vụ chăm sóc ban ngày có nhu cầu sử dụng dịch vụ này cao hơn gấp 4 lần so với nhóm người cao tuổi còn lại (lần lượt là $80,0 \%$ và $20,0 \%$ ), sự khác biệt này có ý nghĩa thống kê với $p<0,05$. Tương tự, như kết luận của nghiên cứu về nhu cầu sử dụng dịch vụ y tế mới - dịch vụ chăm sóc sức khỏe từ xa [8].

\section{KẾT LUÂN}

Nghiên cứu chỉ ra nhu cầu sử dung dich vu chăm sóc nội trú ban ngày sẽ được chú ý và quan tâm hớn khi người dân hiểu rõ hơn về dịch vụ này, đồng thời dịch vụ này cũng sẽ có nhiều khả năng được quan tâm hơn ở những đối tượng có điều kiện về kinh tế. Do vậy, để phát triển các dịch vụ y tế mới trong đó có dịch vụ chăm sóc nội trú ban ngày cho người cao tuổi, cần tăng cường công tác tuyên truyên, quảng bá về loại hình dịch vụ này đến đông đảo người dân và cộng đồng, tập trung ưu tiên nhóm đối tượng có mức kinh tế cao.

\section{TÀI LIẸU THAM KHẢO}

1. Cục thống kê thành phố Đà Nẵng (2020), Niền giám thống kê năm 2019 trên địa bàn thành phố Đà Nẵng.

2. European Telemedicine

Lung Foundation

(2019),

3. Định nghĩa về chăm sóc ban ngày - Daycare, đăng tảai tại link: https://www.msdmanuals.com

4. Nguyển Thị Bảo Ai và cộng sự (2020), Nghiên cứu đặc điểm và nhu cầu chăm sóc bệnh mạn tính ở người cao tuổi tại thành phố Quy Nhợn, tỉnh Bình Đijnh năm 2020.

5. Nguyê̂n văn Sai (2014), Thực trang sức khỏe và nhu cầu chăm sóc y tế của người cao tuổi tại hai huyện tỉnh Hải Dương năm 2013.

6. Trân Thì Hanh (2008). Thực trang chăm sóc sức khỏe tại nhà cho người cao tuổi quận Ô Môn TP. Cần Thớ.

7. Bùi Thùy Dương (2010), Khảo sát nhu câu chăm sóc sức khở ngoài giớ và tại nhà của bệnh nhân và người nhà bênh nhân đến khám bệnh tại Bệnh viện Đại học Y Hà Nội năm 2010.

8. Quách Hữu Trung, Võ Thị Hồng Hướng và cộng sự, Kiến thức và nhu câu về sứ dụng dịch vụ khám chữa bệnh từ xa của bênh nhấn đái tháo đường tại thành phố Đà Nẵng năm 2021.

\section{YẾU Tố ẢNH HƯỞNG ĐẾN SỬ DƯNG VANCOMYCIN AN TOÀN VÀ HIÊ̂U QUẢ TRONG ĐIỀU TRỊ NHIỄM KHUẨN NẶNG TRẺ EM}

\section{TÓM TẮT}

Mục tiêu: Khảo sát các yếu tố ảnh hưởng đến sử dung an toàn và hiệu quả của vancomycin trong điều trị nhiễm trùng nặng trẻ em. Phương pháp tiến hành: Nghiên cứu cắt ngang mô tả các bệnh nhân trẻ em được chỉ định điều trị vancomycin trên 3 ngày. Các trường hợp này được đo nồng đô đáy vancomycin và độ thanh thải creatinin để theo dõi hiệu quả và an toàn của sử dung vancomycin. Kết quả: Nghiên cứu thu nhận 40 trường hợp. Liều lượng vancomycin sử

\footnotetext{
${ }^{1}$ Đại học Y Dược Thành phố Hồ Chí Minh 2Bềnh viện Nhi Đồng 2

Chịu trách nhiệm chính: Hà Mạnh Tuấn

Email: hamanhtuan@ump.edu.vn

Ngày nhận bài: 16.3.2021

Ngày phản biên khoa hoc: 12.5.2021

Ngày duyệt bài: 21.5.2021
}

\section{Hà Mạnh Tuấn ${ }^{1}$, Kim Trần Quan²}

dung trung bình là $55,83 \pm 19,34 \mathrm{mg} / \mathrm{kg} / \mathrm{ngày}$. Nồng độ đáy vancomycin trung vị là $11,09(7,84-16,46)$ $\mu \mathrm{g} / \mathrm{ml}$. Độ thanh thải creatinin trung bình là $80,18 \pm$ $29,14 \mathrm{ml} / \mathrm{min}$. Các yếu tố ảnh hưởng đến sử dụng vancomycin an toàn và hiệu quả là liều lượng vancomycin, cách sử dụng vancomycin và độ thanh thải creatinin. Kết luân. Cần xem xét điều chỉnh liều lượng vancomycin, cách sử dụng vancomycin theo độ thanh thải và nồng đô đáy vancomycin để đảm bảo tính an toàn và hiệu quả trong điều trị.

\section{SUMMARY}

FACTORS AFFECTING THE SAFE AND EFFECTIVE USE OF VANCOMYCIN IN TREATMENT OF SEVERE INFECTIONS IN CHILDREN

Objectives: To investigate the factors affecting the safe and effective use of vancomycin in the treatment of severe infections in children. Methods: 